\title{
Plasma Treatment of Silk Fabrics for Better Dyeability
}

\author{
Yu Iriyama, Takeo Mochizuki*, Makoto Watanabe*, and Makoto Utada* \\ Division of Interdisciplinary Sciences \\ Yamanashi University, \\ 4-4-37 Takeda, Kofu, 400-8510 Japan \\ *Yamanashi Prefectural Fuji Industrial Technology Center \\ 2095 Shimoyoshida, Fujiyoshida, 403-0004 Japan \\ iriyama@edu.yamanashi.ac.jp
}

\begin{abstract}
Silk fabrics were treated with $\mathrm{O}_{2}, \mathrm{~N}_{2}$, and $\mathrm{H}_{2}$ plasmas for deep dyeing and good color fastness to rubbing. C.I. (Color Index) Reactive Black 5 was used as a dye, and color deepness was evaluated by total $\mathrm{K} / \mathrm{S}$. All plasma-treated silk fabrics showed weight loss, especially by $\mathrm{O}_{2}$ plasma. Total $\mathrm{K} / \mathrm{S}$ of dyed silk fabrics treated at $60 \mathrm{~Pa}$ of all plasmas was improved greatly. Total $\mathrm{K} / \mathrm{S}$ increased with increasing plasma treatment time, weight loss of the fabrics in the treatment, and dye concentration in dyeing. They gained greater total $\mathrm{K} / \mathrm{S}$ even dyed in $6 \%$ of dye concentration compared with untreated one dyed in $10 \%$. Color fastness to wet rubbing of silk fabrics was not improved by plasma treatment. However, most of them were still within the level for commercial use.
\end{abstract}

Keywords: plasma treatment, silk fabrics, dyeing, $K / S$, color fastness to wet rubbing

\section{Introduction}

Plasma surface treatment of fiber or fabrics has been applied in many fields for a long time [1-5]. One of the main purposes of the treatment is, in analogy with most of the other materials, the improvement of the surface energy by using hydrophilic-natured plasma. Higher surface energy makes adhesivity or printability better for plastics or any solid materials.

As an application for fabrics (fiber), for example, both organic and inorganic fabrics (fiber) with improved adhesivity or compatibility against plastics by plasma treatment are used for fiberreinforced plastics (FRP), which could raise their performance [6-14].

Another and more important application in plasma treatment of fabrics utilizing higher surface energy is the improvement of dyeability for clothing use. For the purpose of dyeability or color deepening, plasma treatments for many kinds of fabrics, such as poly(ethylene terephthalate), nylon-6, nylon-66, aramid, and wool, have been reported [15-17]. In these researches, chemical interaction between fiber and dye seems to be rather important than just surface energy. In addition, as far as color deepening is concerned, surface morphology of fiber caused by plasma etching is also crucial.

Until recently, reports on plasma treatment of silk were not too many. With increasing popularity of natural products, demands of silk for not only clothing use but also personal-care products and foods have been increasing lately.

Zhang graft polymerized acrylamide on silk fabrics surface by plasma-induced method, and analyzed the surface [18].

Nishikawa et al.prepared fibroin film and treated with $\mathrm{CF}_{4}$ plasma [19]. They intended fluorination of the film, but they could not obtain very hydrophobic surface as they expected. After the immersion of the plasma-treated films in water, they found hydrolysis of peptide bonds mainly caused by $\mathrm{F}^{-}$in the plasma.

Selli et al. treated silk fabrics with $\mathrm{SF}_{6}$ plasma, and they claim that $\mathrm{F}$ replaced $\mathrm{H}$ easily and the 


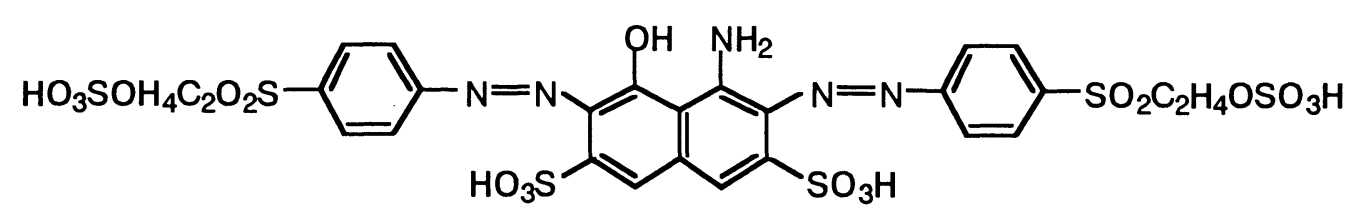

Figure 1. Structural formula of C.I. Reactive Black 5.

fluorination was effective [20].

Nakano et al. measured surface area of $\mathrm{O}_{2}$ plasma-treated silk fabrics with a modified-BET apparatus that they have developed [21]. It will be very interesting if a relationship between the surface area and color deepness is revealed.

As the use of silk fabrics increases, their defects have become clear. In addition to deeper dyeing, improvement of color fastness property is often required. In general, color fastness of silk is not satisfactory. When silk fabrics are rubbed with other clothing, dye on the silk transfers to the other cloths, which is called "color pollution".

In this study, we treated silk fabrics with $\mathrm{O}_{2}$, $\mathrm{N}_{2}$, and $\mathrm{H}_{2}$ plasmas in order to improve color deepness of dyed silk fabrics and improve color fastness to rubbing. The use of plasma technique, in which little waste is produced as a dry process, is also concerned with the "environment".

\section{Experimental}

\subsection{Materials}

Silk fabrics used in this study were provided by Chuo Sen-i Co. Silk threads with three 21-denier fibers each were woven into silk fabrics with the densities of warp and woof 200 and 135 threads per $3.8 \mathrm{~cm}$, respectively. After weaving, the silk fabrics were washed in a soap solution with $\mathrm{Na}_{2} \mathrm{CO}_{3}$ for the removal of sericin. The fabrics were cut into the size of $200 \times 300 \mathrm{~mm}$ for plasma treatments. This length is required for the measurement of color fastness to wet rubbing although the area of the circle of about $200-\mathrm{mm}$ diameter can be treated uniformly.

$\mathrm{O}_{2}, \mathrm{~N}_{2}$, and $\mathrm{H}_{2}$, obtained from Iwatani Sangyo, were used as plasma gases.

C.I.(Color Index) Reactive Black 5 (DyStar Inc., Remazol Black B) was used as a dye, of which structural formula is shown in Figure 1. Sodium sulfate, sodium carbonate (both from Wako Pure Chemical), and nonionic surfactant as a soaping agent (Heian Yushi Kagaku Industry, Soilless HC) were used in the dyeing and soaping processes.

White cotton fabrics used for the test for color fastness to wet rubbing was standard testing fabrics of Japanese Standards Association.

\subsection{Plasma Treatment}

Plasma treatment of silk fabrics was carried out in a plasma treatment apparatus, manufactured by SST Inc., shown in Figure 2. Power electrode (aluminum, 150-mm d.), which is connected to an rf $(13.56 \mathrm{MHz})$ generator via an automatic matching unit, is at the bottom of the reactor. Ground electrode is the whole plate of the top cover of the reactor. The gap between the electrodes was $50 \mathrm{~mm}$.

A piece of silk fabrics was placed on the bottom electrode. The reactor was evacuated with a rotary vacuum pump for $10 \mathrm{~min}$, then plasma gases were introduced into the reactor through a needle valve and the pressure was adjusted to predetermined values $(60-400 \mathrm{~Pa})$. The pressure of the system was monitored with a pirani gauge (Shinko Seiki, PG-MW2).

Plasma discharge power was fixed to $50 \mathrm{~W}$. Plasma treatment time was varied up to $30 \mathrm{~min}$. The bottom electrode was cooled with $25{ }^{\circ} \mathrm{C}$ circulating water during the treatment.

\subsection{Measurement of Weight Loss}

Weight of silk fabrics before and after plasma treatments was measured, and weight loss was calculated. All the fabrics samples were dried at $105{ }^{\circ} \mathrm{C}$ for $30 \mathrm{~min}$ prior to the measurement for the exclusion of the effect of absorbed water.

\subsection{Surface Analysis}

Chemical composition of plasma-treated silk fabrics surfaces was analyzed with X-ray photoelectron spectroscopy (XPS, Shimadzu,

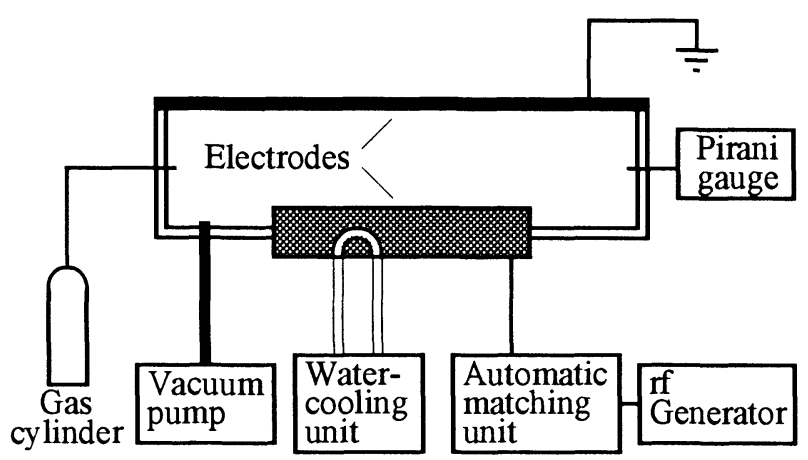

Figure 2. Apparatus for the plasma surface treatment of silk fabrics. 
ESCA-750). Surfaces of plasma-treated silk fabrics were observed with scanning electron microscope (SEM, Elionix, EXM-3500).

\subsection{Dyeing}

Plasma-treated silk fabrics were dyed in a 250 $\mathrm{mL}$ mixture solution of the dye, $\mathrm{Na}_{2} \mathrm{SO}_{4}(40 \mathrm{~g} / \mathrm{L})$, and $\mathrm{Na}_{2} \mathrm{CO}_{3}(4 \mathrm{~g} / \mathrm{L})$ at $50{ }^{\circ} \mathrm{C}$ for $90 \mathrm{~min}$. Four sheets of plasma-treated fabrics were dyed at once. The amounts of the dye dissolved in the solution is normally $10 \%$ of the weight of fabrics to be dyed. In this study, we varied the amounts of the dye from $4 \%$ to $10 \%$. Following the dyeing and rinsing with water, fabrics were cleaned with a $250-\mathrm{mL}$ soap solution at $85^{\circ} \mathrm{C}$ for $15 \mathrm{~min}$ that contains the soaping agent $(2 \mathrm{~g} / \mathrm{L})$ and $\mathrm{Na}_{2} \mathrm{CO}_{3}(2 \mathrm{~g} / \mathrm{L})$. Finally, the fabrics were rinsed with large amounts of water and dried at room temperature.

\subsection{Color Measurement}

For the evaluation of color deepness of dyed silk fabrics, reflectance of visible light from 400 to $700 \mathrm{~nm}$ was measured at every $20 \mathrm{~nm}$ with a reflect meter (Kurabo, AUCOLOR-10a), and K/S value was obtained by Kubelka-Munk equation,

$$
\mathrm{K} / \mathrm{S}=\left\{(1-\mathrm{R})^{2} / 2 \mathrm{R}\right\}-\left\{\left(1-\mathrm{R}^{\prime}\right)^{2} / 2 \mathrm{R}^{\prime}\right\}
$$

where $R$ and $R^{\prime}$ are reflectance before and after dyeing, respectively. $\mathrm{K}$ and $\mathrm{S}$ are absorption coefficient and reflection coefficient of fabrics, respectively. We take total $\mathrm{K} / \mathrm{S}$ value, which is the summation of $\mathrm{K} / \mathrm{S}$ at every $20 \mathrm{~nm}$ in the range between 400 and $700 \mathrm{~nm}$, as an indication of color deepness.

\subsection{Test for Color Fastness to Wet Rubbing}

Test for color fastness to wet rubbing was performed with a friction tester (Daiei Kagaku Seiki) according to Japanese Industrial Standard (JIS) L0849II. As shown in Figure 3, a dyed test piece

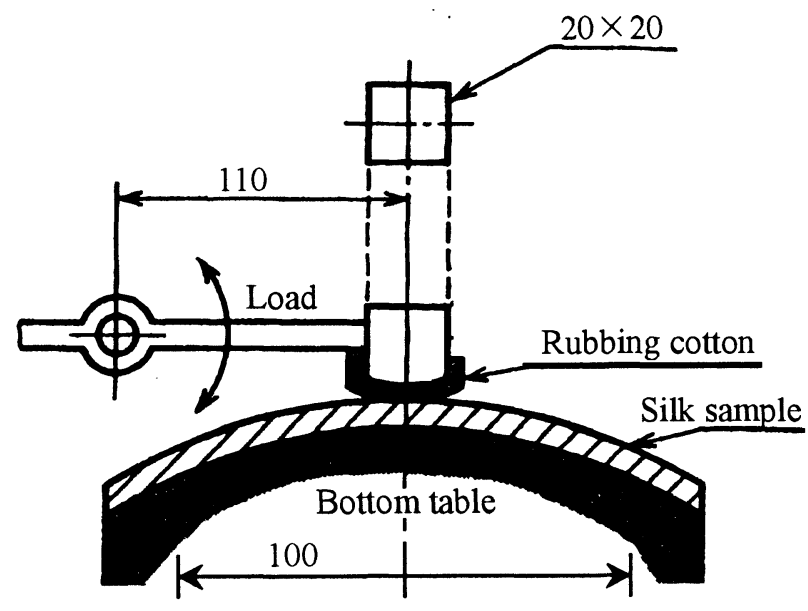

Figure 3. Friction tester for the test for color fastness to wet rubbing. of silk fabrics $(30 \times 300 \mathrm{~mm})$ was placed on the bottom table, on which a rubbing piece of wet white cotton fabrics $(50 \times 50 \mathrm{~mm})$ was pressed down with the load of $2 \mathrm{~N}$. The table was moved back and forth as the following conditions: one-way distance, $100 \mathrm{~mm}$; speed, $100 \mathrm{~mm} / \mathrm{s}$; time, $200 \mathrm{~s}$.

After the test, dye on the dyed silk fabrics surface was found to transfer to the white rubbing cotton
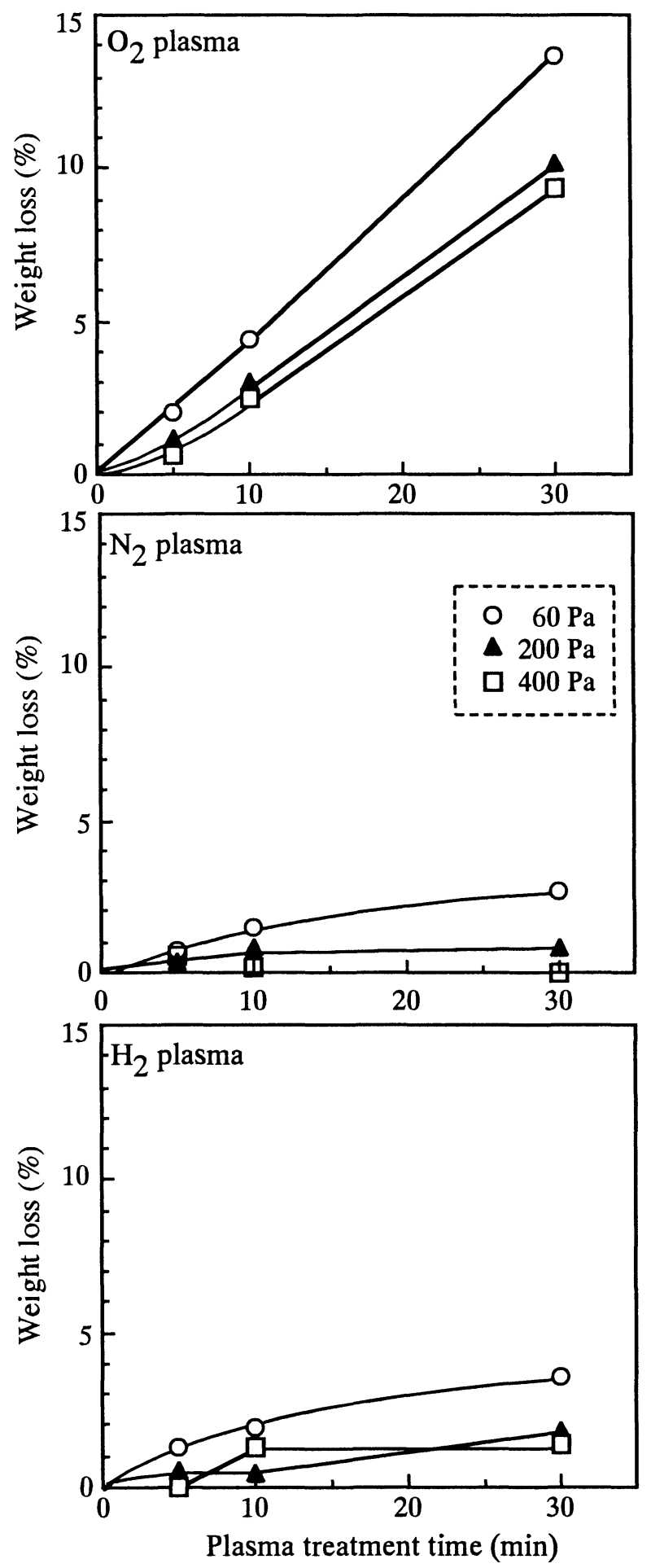

Figure 4. Weight loss of the silk fabrics after plasma treatment in various plasma conditions. 
fabrics slightly. Color fastness was evaluated by the color of the cotton fabrics and graded from Level 1 to Level 5 by human eye, according to JIS. Level 2-3, which indicates Level between 2 and 3, or greater is accepted for commercial use.

\subsection{Friction Test}

Friction coefficient of plasma-treated silk fabrics was measured with a surface tester (Kato Tech, KES-FB4). In this test, a piece of silk fabrics (200 $X 200 \mathrm{~mm}$ ) was set on a bottom table with a tension of $0.2 \mathrm{~N} / \mathrm{cm}$, on which ten pieces of piano wire fixed in parallel in the area of $5 \times 5 \mathrm{~mm}$ were contacted with the load of $0.49 \mathrm{~N}$. When the piano wire moved on the fabrics, friction force was detected and friction coefficient was calculated.

\section{Results and Discussion}

\subsection{Plasma Etching of Silk Fabrics}

In plasma treatments with non-polymer-forming gases, in general, etching of substrates is not negligible. In this study of plasma treatment of silk fabrics, also, etching was observed by weight loss of the fabrics and SEM observation.

Figure 4 shows weight loss of the silk fabrics after plasma treatment in various plasma conditions. In plasma treatments of those non-polymer-forming gases, weight loss of silk fabrics was observed in the most of plasma conditions. As a general trend, in those figures, weight loss was greater at lower pressure $(60 \mathrm{~Pa})$, where etching takes place effectively because of the higher plasma energy density. Among those gases, naturally, the greatest weight loss was observed in $\mathrm{O}_{2}$ plasma.

SEM photographs of plasma-treated silk fabrics (60 Pa, $30 \mathrm{~min}$ ) are shown in Figure 5. Photographs of those treated at $400 \mathrm{~Pa}$ were omitted because no significant difference was observed compared with untreated one even by $\mathrm{O}_{2}$ plasma treatment.

The surface of untreated silk fabrics is very smooth, while those of plasma-treated ones are not. Obviously, that treated with $\mathrm{O}_{2}$ plasma at $60 \mathrm{~Pa}$ was etched the most and showing severe damage on the surface. The etching may not be limited to just surface, because the fibers became thinner. Those treated with $\mathrm{N}_{2}$ and $\mathrm{H}_{2}$ plasmas at $60 \mathrm{~Pa}$ also showed micropittings on the surface.

Although the surface roughness is not measured quantitatively, the roughness seems to have a correlation against the weight loss.

We also measured chemical composition and friction coefficient of the surface, but we will discuss them in the following sections in connection with dyeability and color fastness.

3.2. Dyeability of Plasma-Treated Silk Fabrics

3.2.1. Effect of Plasma Condition

Figure 6 shows total K/S of plasma-treated silk (a)

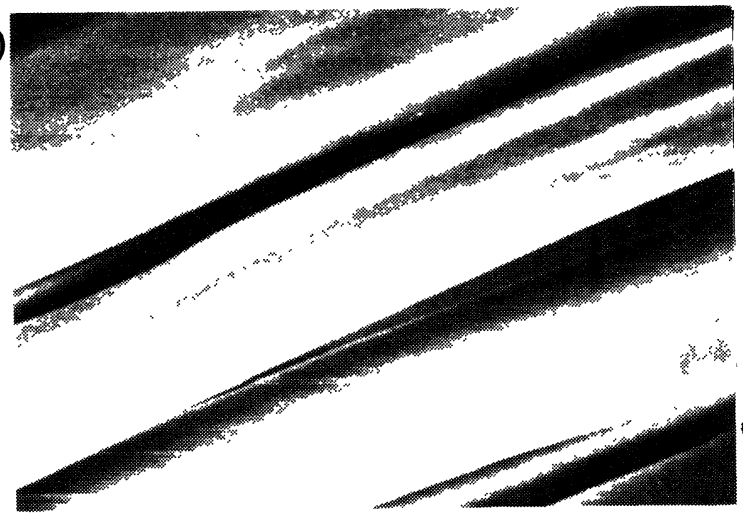

(c)

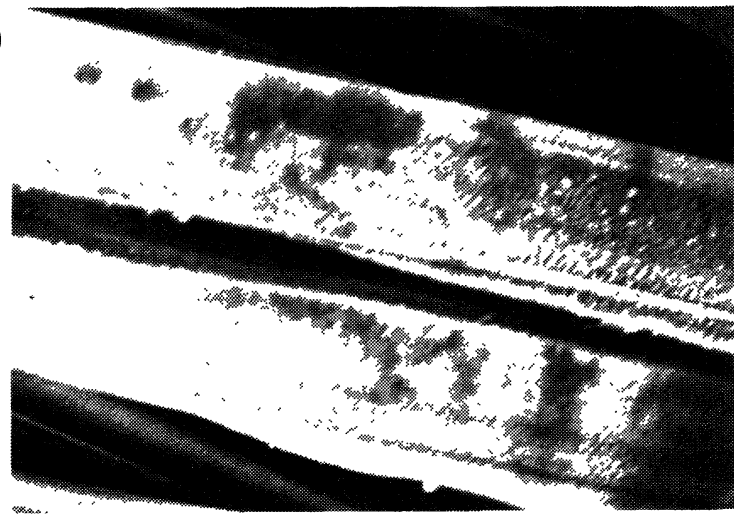

(b)

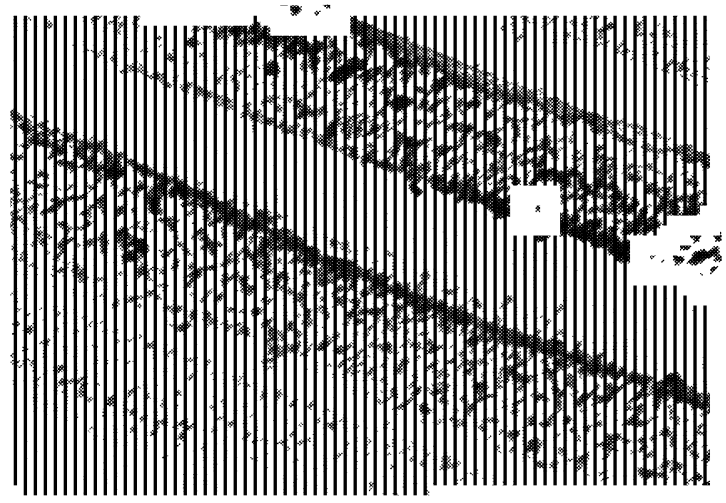

(d)

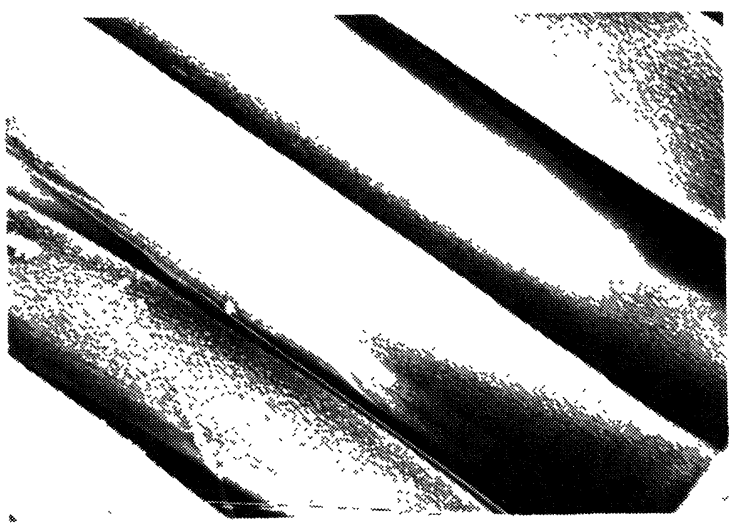

Figure 5. SEM photographs of plasma-treated silk fabrics at $60 \mathrm{~Pa}$ for 30 min. (a) Untreated, (b) $\mathrm{O}_{2}$, (c) $\mathrm{N}_{2}$, (d) $\mathrm{H}_{2}$ plasma. 
fabrics in various plasma conditions after dyed in $10 \%$ dye concentration. Only silk fabrics treated at $60 \mathrm{~Pa}$ showed improved total $\mathrm{K} / \mathrm{S}$, and a dependence of treatment time was found. Among three plasmas, $\mathrm{O}_{2}$ plasma showed the best total K/S: closed 400 by 30 -min treatment, which is an outstanding value for silk fabrics.

Those treated at 200 and $400 \mathrm{~Pa}$ showed almost no change of $\mathrm{K} / \mathrm{S}$ from untreated one. This big
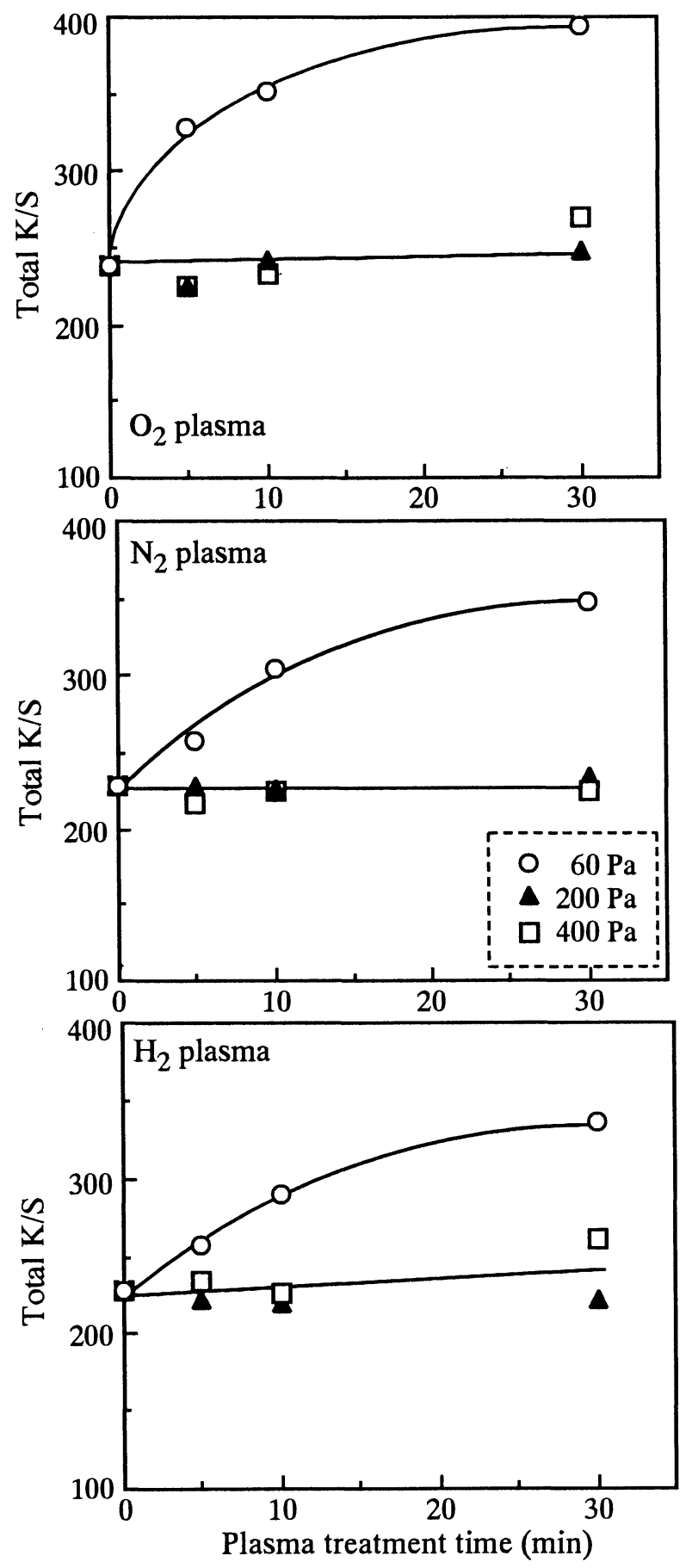

Figure 6. Total $\mathrm{K} / \mathrm{S}$ of plasma-treated silk fabrics in various plasma conditions after dyed in $10 \%$ dye concentration. difference in $\mathrm{K} / \mathrm{S}$ by pressure might have been caused by etching, as we indicated the previous section: lower pressure gains higher plasma energy density, which is preferable to etching.

3.2.2. Effect of Surface Chemical Composition

After plasma treatment, chemical composition of silk fabrics surface was estimated from the results of XPS measurement. After $\mathrm{O}_{2}$ plasma treatment, $\mathrm{O} / \mathrm{C}$ increased greatly and $\mathrm{N} / \mathrm{C}$ increased slightly. After $\mathrm{N}_{2}$ plasma treatment, both $\mathrm{O} / \mathrm{C}$ and $\mathrm{N} / \mathrm{C}$ increased slightly, while the both decreased slightly after $\mathrm{H}_{2}$ plasma. The dye used in this experiment (C.I. Reactive Black 5, shown in Fig.1) has many acidic and a basic functional groups. Therefore, more interaction between the dye and silk fabrics is expected if there are more functional groups on the silk surface, especially basic groups, which should result in deep dyeing.

Figure 7 shows the relationship between atomic ratios, $\mathrm{O} / \mathrm{C}$ and $\mathrm{N} / \mathrm{C}$, and total $\mathrm{K} / \mathrm{S}$. At a glance, the data are fitted well to two lines. However, both the lines are parallel to the abscissa, which denies the dependence of $\mathrm{O} / \mathrm{C}$ or $\mathrm{N} / \mathrm{C}$. In the first place, however, the lines are not distinguishing the data sets of $\mathrm{O} / \mathrm{C}$ and $\mathrm{N} / \mathrm{C}$. The two lines were identified by the pressure at plasma treatment: silk fabrics treated at 60 and $400 \mathrm{~Pa}$ shows different dyeability although the atomic ratios are in the same range. It may be a coincidence, but it is interesting that the both $\mathrm{O} / \mathrm{C}$ and $\mathrm{N} / \mathrm{C}$ fitted to a same line for a same pressure. From the results above, color deepness was found to be more sensitive to plasma condition rather than simple surface chemical composition. An effect of etching caused at lower pressure may be important.

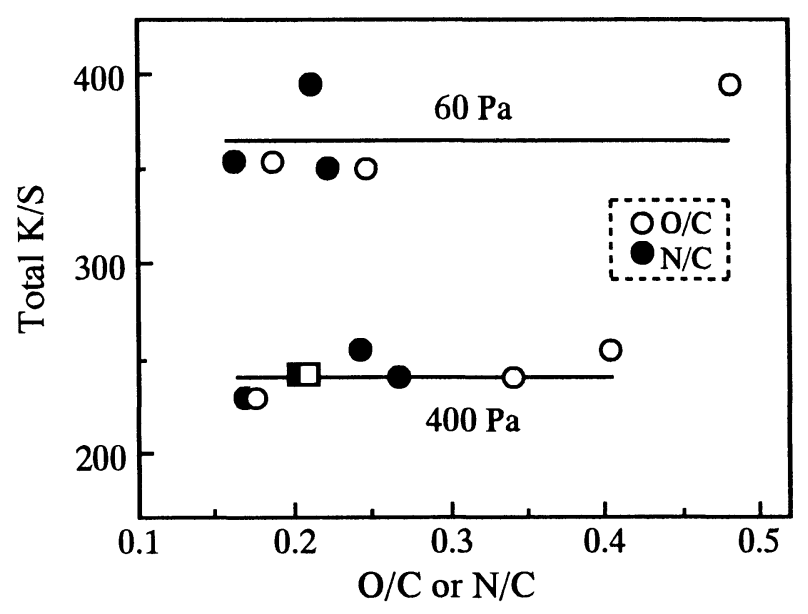

Figure 7. Relationship between atomic ratios, $\mathrm{O} / \mathrm{C}$ and $\mathrm{N} / \mathrm{C}$, and total K/S. Dye concentration, $10 \%$; plasma condition, $30 \mathrm{~min}$; $\square$, untreated. 
Also in our preliminary study, we treated silk fabrics with $\mathrm{NH}_{3}$ plasma in order to form amino group positively. We found considerably increased $\mathrm{N}$ on the silk fabrics, but total K/S did not increase as we expected. The clarification of the mechanism of dyeing and more precise analysis of functional groups are required.

3.2.3. Effect of Dye Concentration

Figure 8 shows total $\mathrm{K} / \mathrm{S}$ of plasma-treated silk


Figure 8. Total $\mathrm{K} / \mathrm{S}$ of plasma-treated silk fabrics at $60 \mathrm{~Pa}$ after dyed in various dye concentrations. fabrics at $60 \mathrm{~Pa}$ after dyed in various dye concentrations.

As general trends for all three plasmas, total K/S increases with increasing plasma treatment time and dye concentration. Since the normal dye concentration is $10 \%$, total $\mathrm{K} / \mathrm{S}$ value of $10 \%$ dye concentration with 0 -min treatment is regarded as the standard. All plasma-treated silk fabrics samples showed higher total $\mathrm{K} / \mathrm{S}$ values than untreated ones in the corresponding dyeing conditions.

In $\mathrm{O}_{2}$ plasma treatment, although all samples dyed in $4 \%$ did not reach the standard, those dyed in $6 \%$ and $8 \%$ were better than the standard even 5-min treatment.

In $\mathrm{N}_{2}$ plasma treatment, total $\mathrm{K} / \mathrm{S}$ of $10-\mathrm{min}$ treated silk fabrics in $8 \%$ and $6 \%$ was almost the same level as the standard. 30-min treated one had the best total $\mathrm{K} / \mathrm{S}$ in all dye concentrations, and that dyed in $4 \%$ also topped the standard.

In $\mathrm{H}_{2}$ plasma treatment, most of the samples dyed in $6 \%$ and $8 \%$ showed better total $\mathrm{K} / \mathrm{S}$ than the standard.

From those results, plasma treatment is obviously useful in dyeing: greater total $\mathrm{K} / \mathrm{S}$ can be obtained in the same dye concentration, or the same total $\mathrm{K} / \mathrm{S}$ can be obtained in less dye concentration, which could lead to great saving of dye. The dye concentration can be reduced to as low as $6 \%$, depending on the plasma condition.

The reduction of dye concentration also contributes to the reduction of load on the environment. After the dyeing,, solid materials (mainly dye) in the used dye solution are usually separated and burned because pure dye is difficult to be recovered from it. In the series of this waste treatments, it is obvious that less dye contents consume less energy and produce less waste.

3.2.4. Effect of Weight Loss (etching and surface morphology)

Surface roughness (morphology) is a key factor for the color deepness of dyed fabrics. Appropriate roughness enables the surface to hold more dyes and cause random scattering, which results in deep color appearance. Instead of surface roughness, because we have not measured it quantitatively, we examined the effect of weight loss on total K/S.

Figure 9 shows relationship between total K/S and weight loss in the plasma treatment for all plasma gases treated at $60 \mathrm{~Pa}$ after dyed in various dye concentrations. There is a clear dependence between them. Total K/S increases with weight loss, and there is little difference among $6-10 \%$ of dye concentration. Only $4 \%$ is parted from them at lower total $\mathrm{K} / \mathrm{S}$. We cannot state the surface 


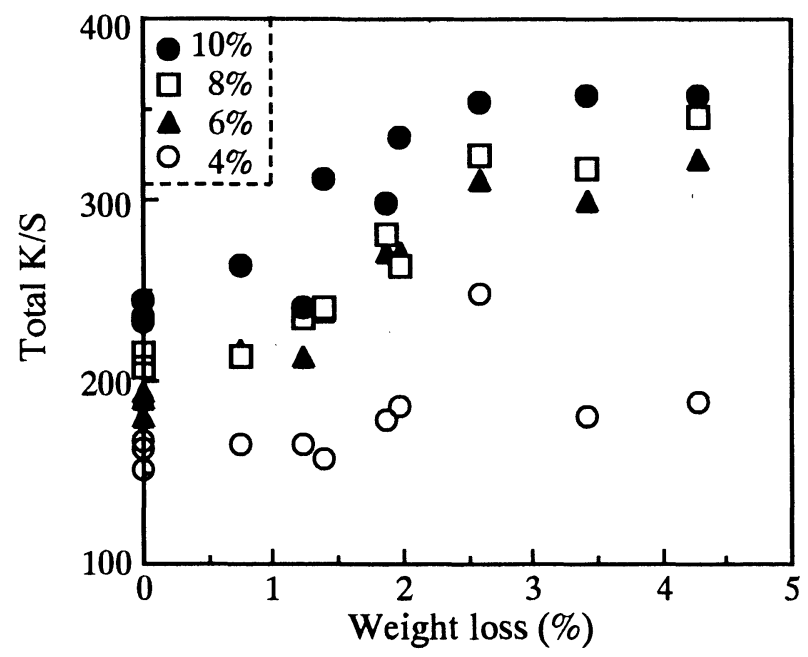

Figure 9. Relationship between total K/S and weight loss in the plasma treatment for all plasma gases treated at $60 \mathrm{~Pa}$ after dyed in various dye concentrations.

morphology accurately, but it was found that more etched silk fabrics in any plasma condition had higher total K/S.

\subsection{Color Fastness to Wet Rubbing}

Results of color fastness to wet rubbing of plasma-treated silk fabrics at $60 \mathrm{~Pa}$ after dyed in various dye concentrations are shown in Figure 10. The results are graded from Levels 1 to 5 by human eye. Following a convention, we express a level between, for example, 2 and 3 as Level 2-3. Level 5 shows the best performance in color fastness, and Level 2-3 or higher is acceptable for commercial use.

Other than the judge above, we tried to evaluate the amounts of transferred dye quantitatively, and analyzed the stained cotton fabrics with XPS. However, the amount of the dye on the cotton fabrics was so little that XPS could not detect it at all. Judging by human eye seems to be quite reliable.

In the figure, the color fastness of untreated silk fabrics was Level 3-4. The color fastness depends on not only plasma treatment condition but also dye concentration in dyeing. In general, dyed fabrics with higher $\mathrm{K} / \mathrm{S}$ (higher color deepness) show lower color fastness. Although higher $\mathrm{K} / \mathrm{S}$ is achieved by dyeing in higher dye concentration, color fastness becomes worse. The same thing can be said to plasma-treated silk fabrics. Most of plasma-treated silk fabrics had better $\mathrm{K} / \mathrm{S}$ but it was difficult for them to hold the color fastness at higher levels.

In addition to the simple discussion with total $\mathrm{K} / \mathrm{S}$, we should consider the effect of surface morphology on the color fastness. Surface roughness may be one of the factors for higher $\mathrm{K} / \mathrm{S}$, but it can cause higher friction during the rubbing in the test
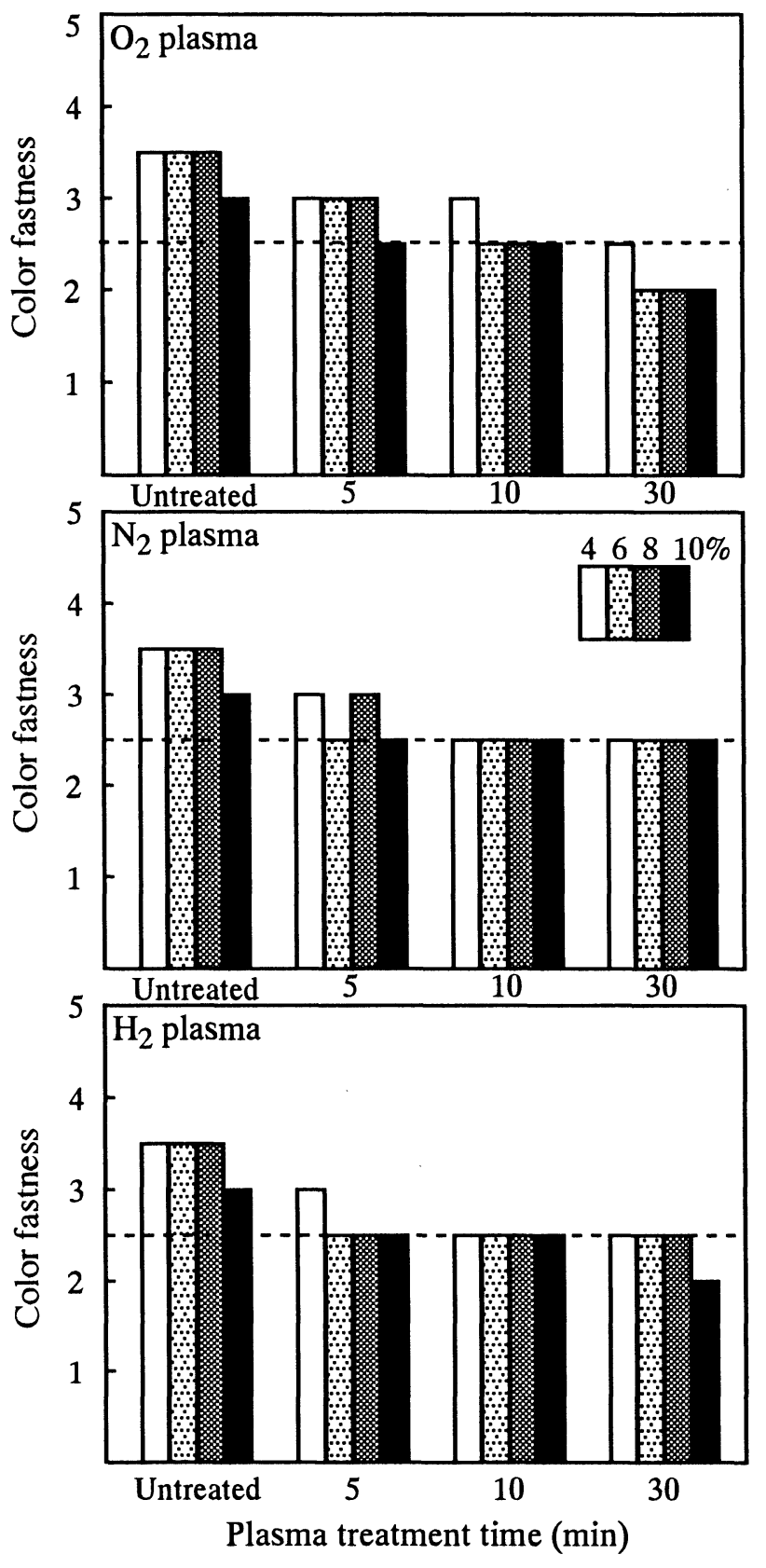

Figure 10. Results of color fastness to wet rubbing of dyed plasma-treated silk fabrics in various dye concentrations. Plasma condition, $60 \mathrm{~Pa}$.

for the color fastness. Therefore we measured the friction coefficient of the plasma-treated silk fabrics. Results are shown in Table 1 . The friction coefficient of untreated silk fabrics is 0.216 , while those of $\mathrm{O}_{2}$, $\mathrm{N}_{2}$ and $\mathrm{H}_{2}$ plasma-treated silk fabrics are around 0.7-0.8. It was naturally expected from the SEM photographs (Fig.5), the roughest $\mathrm{O}_{2}$ plasma-treated silk fabrics had the highest coefficient. The higher friction coefficient will easier to damage the fabrics surface in rubbing and will hurt the color fastness.

It is easy for the plasma treatment to improve color deepness, but too much treatment spoils color 
Table 1. Friction coefficient of plasma-treated silk fabrics.

\begin{tabular}{cc}
\hline Treatment & Friction coefficient \\
\hline Untreated & 0.216 \\
$\mathrm{~N}_{2}$ plasma & 0.673 \\
$\mathrm{O}_{2}$ plasma & 0.803 \\
$\mathrm{H}_{2}$ plasma & 0.730 \\
\hline
\end{tabular}

Plasma condition, $60 \mathrm{~Pa}$ and $30 \mathrm{~min}$.

fastness. Rather than etching-favored $\mathrm{O}_{2}$ plasma, $\mathrm{N}_{2}$ or $\mathrm{H}_{2}$ plasma with short treatment may be the ultimate condition to settle both the color deepness and color fastness.

\section{Conclusion}

Weight loss of silk fabrics was observed in the most conditions of $\mathrm{O}_{2}, \mathrm{~N}_{2}$, and $\mathrm{H}_{2}$ plasma treatments. Total K/Sof dyed silk fabrics increased considerably by the plasma treatment at $60 \mathrm{~Pa}$. Plasma-treated fabrics that dyed in lower dye concentration, as low as $6 \%$, exhibited comparable total $\mathrm{K} / \mathrm{S}$ to untreated one dyed in $10 \%$, which could lead to great savings of dyes. Dependence of weight loss on total $\mathrm{K} / \mathrm{S}$ was observed but that of surface chemical composition, $\mathrm{O} / \mathrm{C}$ and $\mathrm{N} / \mathrm{C}$, was not. Color fastness to wet rubbing of the dyed silk fabrics was not improved by the plasma treatment. However, it was still within the level for commercial use.

\section{Acknowledgments}

The authors are grateful to Ms. N. Ajisaka and Mr. K. Taoka for the measurements of XPS and SEM.

\section{References}

1. Y. Iriyama, T. Yasuda, D. L. Cho, andH. Yasuda, J. Appl. Polym. Sci., 39, 249(1990).

2. T. Wakida, T. Goto, H. Li, T. Sato, M. Lee, and J. Chen, Sen'i Gakkaishi, 50, 533 (1994).
3. K. Miyazaki, K. Hisada, T. Hori, and N. Watanabe, Sen'i Gakkaishi, 55, 408 (1999). (in Japanese)

4. K. W. Oh, S. H. Kim, E. A. Kim, J. App. Polym. Sci., 81, 684 (2001).

5. Y. Qiu, C. Zhang, Y. J. Hwang, B. L. Bures, and M. McCord, J. Adhes. Sci. Technol., 16, 99 (2002).

6. T. Ihara, T. Matsuoka, and Y. Iriyama, J. Adhes. Sci. Technol., 10, 823 (1996).

7. Y. Iriyama, M. Taira, T. Ihara, and T. Matsuoka, J. Photopolym. Sci. Technol., 10, 139 (1997).

8. R. Li, L. Ye, and Y.-W. Mai, Composites, 28A, 73 (1997).

9. S.-G. Lee, T.-J. Kang, and T.-H. Yoon, J. Adhes. Sci. Technol., 12, 731 (1998).

10. N. Inagaki, S. Tasaka, T. Inoue, J. Appl. Polym. Sci., 69, 1179 (1998).

11. S. I. Moon and J. Jang, J. Mater. Sci., 33, 3419 (1998).

12. K. Yamada, T. Haraguchi, and T. Kajiyama, $J$. Appl. Polym. Sci., 75, 284 (2000).

13. C. Zhang, V. S. Gopalaratnam, and H. K. Yasuda, J. Appl. Polym. Sci. , 76, 1985 (2000).

14. K. F. Koster and P. Schwartz, Compos. Sci. Technol., 60, 2005 (2000).

15. S. Kobayashi, T. Wakida, S. Niu, S. Hazama, C. Doi, T. Ito, and Y. Sasaki, J. Soc. Dyers Colour., 111, 72 (1995).

16. T. Oktem, H. Ayhan, N. Seventekin, E. Piskin, J. Soc. Dyers Colour. 115, 274 (1999).

17. C.I.Jahagirdar and Y. Srivastava, J. App. Polym. Sci., 82, 292 (2001).

18. J.Zhang, J. App. Polym. Sci. , 64, 1713 (1997). 19. A. Nishikawa, H. Makara, N. Shimasaki, Sen'i Gakkaishi , 50, 274 (1994). (in Japanese)

20. E. Selli, C. Riccardi, M. R. Massafra, B. Marcandalli, Macromol. Chem. Phys., 202, 1672 (2001).

21. S. Nakano, T. Isono, M. Furutani, T. Senzaki, and M. Suzuki, Sen'i Gakkaishi, 50, 136 (1994). (in Japanese) 